\title{
Theoretical and practical backgrounds of monitoring system of ship power transmission systems' torsional vibration
}

\author{
Lech Murawski $^{1}$ (1) $\cdot$ M. Dereszewski ${ }^{1}$
}

Received: 13 December 2018 / Accepted: 12 April 2019 / Published online: 23 April 2019

(c) The Author(s) 2019

\begin{abstract}
Reliability of the marine propulsion system is closely correlated with the safety of navigation at sea. Typical ship's powertrain has a lot of advantages (mainly efficiency) but is the source of high vibration level. What is more, rough sea conditions can be a source of additional ship vibration, especially for big container ships. Vibrations may have a dangerous influence on ship equipment's strength and consequently on the ship's safety. Torsional vibrations of the marine power transmission system are usually the most dangerous for the shaft line and the crankshaft. The power of propulsion system is quite often measured by commercial measuring device based on instantaneous angular speed (IAS). The angular speed measurements are performed using two optical sensors for reading the IAS, mounted at shaft line. The authors try to use existing apparatus for torsional vibrations' continuous monitoring. Designing monitoring methodology consists several analytical methods. Simplified method of torsional vibration calculation is a first one. Simplified calculation method gives us a determination possibility of torsional vibrations in typical and emergency working conditions. Natural frequency value (resonance location) as well as vibration amplitudes can be estimated on the base of the method. The presented calculation method was verified by comparison with the detailed finite element method calculation and measurements on real ships. The second part of the monitoring system contains methodology of monitoring of piston engine's crankshaft torsional vibrations by measurement of IAS at free and power output ends of the engine's crankshaft. It is assumed that calculation of differential value between both ends shall give the picture of torsion angle magnitudes and phases of the peak values. Analysis method of recorded signals (e.g., recalculation of angular distance sampling into constants time function and frequency base by FFT analysis) is also developed. Description of the measurements of the crankshaft torsional vibration for marine engine with some simulated malfunction (a leak of fuel injection pump, and relayed on mounting of sets of injection valves with different nozzles characteristics-spraying nozzle angle) is presented. Presented results of experiment derive from test cycle carried out using laboratory stand of Gdynia Maritime University equipped with 3-cylinder self-ignition engine, powering electric generator. The planned monitoring system should have detecting possibility of torsional vibration changes (propulsion system malfunction), the ability to assess the degree of danger of failure and eventually determination of the risk of damage and the causes of propulsion system's threat failure.
\end{abstract}

Keywords Torsional vibration · Marine propulsion system · Power transmission system $\cdot$ Condition monitoring $\cdot$ Optical method of measurement

\section{Introduction}

Lech Murawski

1.murawski@wm.am.gdynia.pl

M. Dereszewski

m.dereszewski@wm.am.gdynia.pl

1 Gdynia Maritime University, ul. Morska 81-87, 81-225 Gdynia, Poland

Diesel engines are one of the most critical mechanisms having impact on safety of shipping. Unpredicted failures of engines, installed on board as main propulsion or electro-generators units can result with serious consequences, jeopardizing human life and environment. Nowadays, twostroke, slow-speed main engines have been installed mostly on merchant ships. The engines are connected to a directly driven propeller by a relatively short shaft line. Described 
propulsion system has a lot of advantages (mainly efficiency) but is the source of a relatively high vibration level $[1,2]$. Many authors examine the vibration characteristics and vibration control of complex ship hull structures [3]. But still, the propulsion system is a main source of ship vibration and methodology of power transmission system analysis is very important from designers' point of view.

Authors have realized that modern engines released by leading manufacturers, for last couple of years are strongly equipped with systems dedicated to on-line diagnosis, such as mentioned by reviewer's continuous cylinder pressure monitoring and systems of torsional vibration monitoring, based on different types of encoders. Utility of above-mentioned ones has been obviously proved and is not a subject for discussion, however, dozens of ship-owners run units powered by all types of engines; two and four stroke, low, medium and high speed, which are not equipped with control systems, but still jeopardized on overload and stressderivative risks. Presented method is in general dedicated for poorly equipped main engines, when only periodical cylinder pressure indication is an routine, for main engines not equipped with indication cocks and broad spectrum of diesel generators. Presented system is easy to mount and can be fitted to different shaft diameters and places with limited space. Presented in the paper measurement discs are only test samples, can be manufactured using 3D printer with required numbers of teeth and matching to an object dimensional constraint diameters.

The paper presents two essential elements of future monitoring system of marine power transmission systems' torsional vibration. First one is diagnostic of proper working conditions of main engine based on torsional vibration measurements. Theoretical foundations are presented in Sects. 2 and 3 and the preliminary application of measurement system is presented in Sect. 5. Structural health monitoring (SHM) system should have possibility of failure detection. Reasons ascertainment for incorrect main engine work is another step of condition monitoring. In the next step autonomous system should give information to the crew about recommendation of optimal exploitation parameters in the emergency working conditions. In the second part of the paper (Sect. 4), simplified method (which is possible to apply in the autonomous SHM systems) of torsional vibration estimation is presented. The possibility of damage detection of engine working parameters by the measurement system was presented in the last part of the article-Sect. 5 . It has been proven that different failures of the marine propulsion system can be detected on the base of torsional vibrations irregularities. Lifetime prediction and diagnostic automation will be the last level of planned SHM.

In internal combustion piston engines, reciprocating movement of pistons is converted to rotary movement of the crankshaft. The angular speed is strongly affected by tangential force coming from gas pressure and vertical imbalance inertial forces induced by reciprocating masses of piston and connecting rod. The character of acting forces lets assume that instantaneous angular speed (IAS) can be utilized for detecting engine faults related to combustion process. Because of sequential ignition in cylinders and differences of combustion quality (i.e., burning process speed and duration, heat emission, pressure expansion) occurring between cylinders, angular speed of a crankshaft is not uniform. Variations of instantaneous angular speed value are reflecting level of unsteady character of subsequent pistons' contribution. Pressure of combustion gases is transformed to a crankshaft in form of variable force, which depends on pressure value and crankshaft position; that force creates torque necessary for attached driven mechanism movement. In our case that was electro-generator producing alternate current. Superposition of instantaneous values of torques coming from driving engine and driven generator, with opposite vector direction, is reason for torsional vibrations of the shaft. Due to origin of occurring forces, character of torsional vibrations shall reflect quality of combustion forces.

Torsional vibrations are the result of the pulsing torque of the reciprocating combustion engine [4] as well as unsteady propeller power output and the torsional elasticity of the power transmission system. All system components such as crankshaft, intermediate shaft, propeller shaft, optional couplings and gears have to transmit the static and additionally dynamic torque. Research methods of the torsional vibration have been developed since the 1950s [5, 6]. Despite such an intense research several elements still need to be investigated, for instance: propeller damping, cylinder damping, polar moment of inertia of propeller added water mass as well as the characteristics of specific shaft line elements such as dampers, gears, elastic couplings. What is more, torsional vibration is one of the main sources of coupled longitudinal vibration and dynamic excitations (on the thrust bearing) of the ship hull and deckhouse.

\section{Monitoring of torsional vibration by instantaneous angular speed measurement}

The main goal of carrying out the investigation was to answer the question whether IAS signal coming out from both ends of the crankshaft can be a source of information about combustion irregularity and whether level of torsional vibration can be controlled using IAS measuring method.

Working condition and performance of self-ignition engines in general depend on combustion process. IAS signal directly reflects effect of various exciting torques associated with combustion dynamics [7]. Because of that, it can be used to diagnose combustion-related faults. Optical 
IAS measurement of diesel engine has advantages of simple and convenient installation of encoders, long service life and reliable work, thus it is very promising to develop that technology for detecting failures of cylinder work condition [8].

General idea of torsional vibration observation relays on simultaneous measurement of the distance done by opposite ends of the shaft. Twist of the crankshaft is result of difference of the angular distance done by the two random points placed on shaft's opposite ends circumference (see Fig. 1). To determine the differential value of the distance, simultaneous measurement of angular speed of both ends of the shaft is necessary. Value of angular shift at perpendicular plains is to be calculated by Eq. 1. If the angular shift is known the torsion moment (torque) can be easily estimated (static as well as dynamic component). Expected torsional vibration stress level can be calculated by SHM system on the base of Eq. 9 (Sect. 4). Stresses measured by IAS can be compared with stresses estimated by SHM system based on the empirical calculations. In case of significant differences the system will signalize possible failure in the propulsion system.

$\varphi=\left(\omega_{A}-\omega_{B}\right) \cdot \tau$,

where $\omega_{A}, \omega_{B}$ represent the angular speed of points $A$ and $B$; $\tau$ represents the time of speed measurement.

Accuracy and reliability of measurement depends on relation between torsions frequency and sampling frequency. In the worst case, torsional changes can take place in the time between subsequent samples and torsion will not be detected. In presented system, the disc A mounted at free end of the crankshaft plays the role of "master" gage and is reference for time counting. The angular speed of the second one, in "slave" position was calculated using time interval determined by master disc. It was assumed that basic measurement sample is a pair of slot-tooth, and number of impulses registered for such pair is the base of time calculation.

For measurement of IAS encoder in form of perforated disc was implemented with windows placed at edge of the disc. All windows have the same dimensions and angular distance between them is $2^{\circ}$. Number of windows is 90 , and then windows are separated by 90 "teeth" with the same span $2^{\circ}$. Rotating disc cuts laser ray pointed at disc's

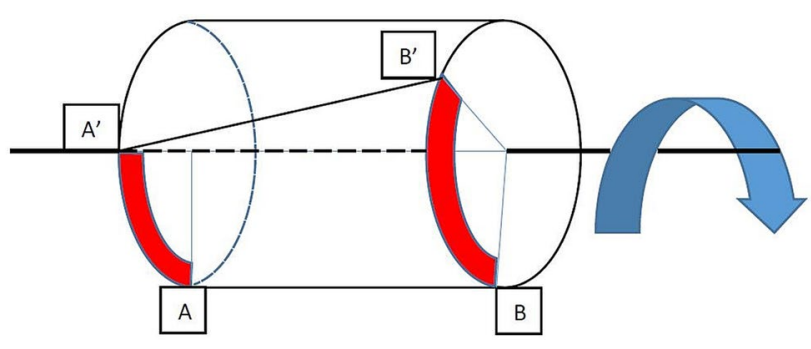

Fig. 1 General idea of torsion measurement as differential value of displacement of points $A$ and $B$ edge in middle of windows' zone. Measurement head, " $u$ " shaped form, consists of a laser from one side and a photodiode at opposite arm. Laser impulses, emitted with frequency of $16 \mathrm{MHz}$ going through windows create signal with value " 1 " and stopped by tooth gives blind signal value " 0 ". This mode of operations lets measure time of passing angular width of tooth and window, in form of a number of registered impulses. Above-presented mode of operations must lead to the conclusion that accuracy of preparation of windows and equality of their dimensions are crucial for accuracy of measurements. In practice, that inconvenience can be partly omitted by taking for calculation an angle of a pair window-tooth, eventually bigger or smaller window's size is compensated by tooth dimension because total angular distance must be equal to $360^{\circ}$.

It should be stressed that the basis of torsion calculation is comparison of angular speed of two discs settled at a shaft with certain distance. Due to that, accuracy of IAS measurement is critical. Angular speed is determined as relation between angular width of a tooth (slot) and time of passing such angle, but time is expressed by number of "laser pings" registered by diode (low voltage for tooth and higher for slot). Number of impulses divided by laser impulses frequency gives passing time, because of which high frequency of emission makes time counting very accurate. In case of low laser emission frequency, the edge of a tooth is hard to detect, what affects accuracy. Moreover, high frequency of emission is necessary for high-speed engines. The second point having impact at accuracy is a width of tooth. It is obvious that higher number of teeth gives more accurate measurement, but makes more complicated elaboration of discs. Taken for experiment width was intentional; to check whether $4^{\circ}$ discretion is enough accurate.

To mark the position of the disc in correspondence to the crankshaft position, the trigger in a form of one additional window (slot) narrow and asymmetric is to be placed in the zone of one tooth. The slot must be placed at a position "cutting" laser ray when piston in first cylinder is in TDC (Top Dead Centre). It lets allocate every part of IAS record to the crankshaft angle and specific cylinder, what is absolutely necessary for further diagnostic analyses. Number of impulses registered for every slot-tooth pair is different and is in functional relation with instantaneous angular speed of the disc. Instantaneous angular speed is presented in the following equation:

$\omega=\frac{\left(\frac{2 \pi}{w}\right) f}{i}[\mathrm{rad} / \mathrm{s}]$,

where $\omega$ represents the angular speed; $w$ represents the number of pairs "slot-tooth"; $i$ represents the number of impulses 
register for pair window-tooth; $f$ represents the frequency of laser emitter.

It would be very complicated to install two discs in exactly the same position against TDC at both ends of the shaft. Most accurate installation would bear the error with value of slit dimension. To avoid above problem, displacement of master disc was referenced to "start slot" but angular instantaneous displacement of the second disc was calculated by multiplication of average speed resulting from impulses calculation by time when master disc does the angular way of slot and tooth. Of course that approach to the problem requires verification of accuracy. Of course that mode of thinking is correct only for first pair, repetition of the way for second pair slotwindow, subsequent calculation must take under consideration already done angular distance and is described by the following equation:

$\Phi_{n}=\sum_{i=1}^{n}\left(\omega_{A i} \cdot \tau_{A i}\right)-\sum_{i=1}^{n}\left(\omega_{B i} \cdot \tau_{A i}\right)$.
Above formula provides us with data set containing number of $i$ values of angular shifts between shaft ends in domain of crank angle, what is the measure of torsional vibration. Figure 2 presents an example of torsional displacement of the shaft in domain of crank angle. It can be observed that the wavelet of the angular speed of both ends of the shaft is different and it is reflected by angular position of shaft's ends.

The form of the torsional displacement shows the character of excitation due to action of three cylinders. The peak value interval is $240^{\circ}$ what is equal to ignition intervals of 3-cylinders, 4-stroke engine. Value of deflection together with data about shaft's dimensions and material enables calculation of share stress and twisting force. In Fig. 3 measurement discs and heads mounted at free end of the engine, and free end of the generator are presented. Data collecting block starts measurement simultaneously for both discs what gives possibility of speeds comparison.
Fig. 2 Torsional deflection of the shaft in time of two revolutions $\left(720^{\circ} \mathrm{CA}\right)$
Fig. 3 Discs and measuring heads mounted at engine's crankshaft end
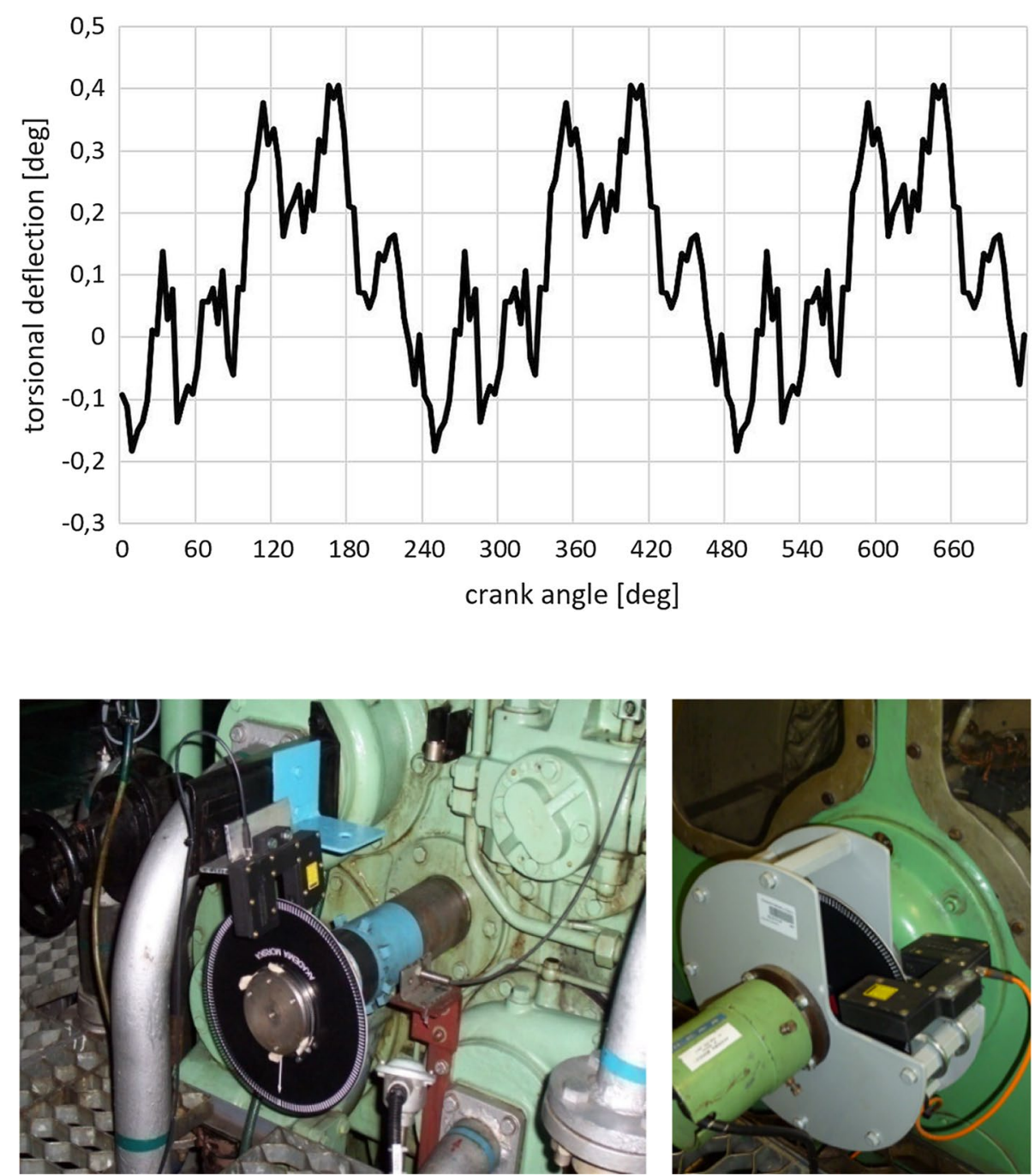


\section{Verification of measurement method's reliability and accuracy}

The tested engine was a diesel generator $-50 \mathrm{~Hz}$ system what was determined governor adjustment at $750 \mathrm{rev} / \mathrm{min}$. The goal of experiment was determination of method's effectiveness in way of trials at loads encompassing all possible conditions of normal exploitation with constant revolutionary speed. The power transmission system of the diesel generator is designed in such a way that torsional resonant revolutions are placed as far as possible from the nominal engine speed. From research point of view it is inconvenience because torsional stress level is relatively low in the nominal engine angular speed. To detect torsional variations, tests at lower and higher than basic speeds were conducted. Different construction of fuel valves were implemented to test for system accuracy. It was assumed that if such minor differences can be registered and detected, identification of more serious problems can be possible. Difference between fuel valves was distinguished, but only at low load.

Presented measurement method has two hesitation points which has to be verified. The firs weak point is discrete nature of measurement discs. Based on the row data from the discs, one can only calculate mean angular speed in distance of slot and tooth pair, what in our case is $2^{\circ}$. Because of comparative nature of measurements, is absolutely necessary to verify level of potential deviations between data coming from both ends of the shaft. Despite torsional character of revolutionary speed, average angular speed of two ends of the shaft must be equal and arithmetical sum of instantaneous torsional deflections must be close to 0 , it means that level value of $\Phi_{n}$ for $n=90$, $180, \ldots$, i.e., for full revolutions, must be at level of single torsion. To verify the above, several measurements under various loads were carried out. Results (Table 1) are presented in form of irregularity deviation index, calculated as proportion of differential value to mean value. Obtained results of angular speed deviations between front and rear discs enable coming out with conclusion that error is very low and can be omitted (Table 1).

$\gamma=\frac{2\left(\omega_{A}-\omega_{B}\right)}{\omega_{A}+\omega_{B}}$.

Calculated values of angular distance according to Eq. 3, of discs $A$ and $B$, are presented in Table 2. It is worthy of
Table 2 Comparison of calculated angular distance for subsequent revolutions

\begin{tabular}{llcc}
\hline Engine's load & $\begin{array}{l}\text { Number of subse- } \\
\text { quent revolution }\end{array}$ & $\begin{array}{l}\text { Distance of } \\
\operatorname{disc} A(\mathrm{rad})\end{array}$ & $\begin{array}{l}\text { Distance of } \\
\operatorname{disc} B(\mathrm{rad})\end{array}$ \\
\hline $100 \mathrm{~kW}$ & 1 & 6.287 & 6.283 \\
& 2 & 12.566 & 12.566 \\
& 3 & 18.854 & 18.850 \\
$140 \mathrm{~kW}$ & 1 & 6.278 & 6.283 \\
& 2 & 12.566 & 12.566 \\
& 3 & 18.845 & 18.850 \\
& 1 & 6.284 & 6.283 \\
& 2 & 12.566 & 12.566 \\
& 3 & 18.851 & 18.850 \\
\hline
\end{tabular}

underlining that after two revolutions (row number 2 in Table 2), under every considered load, torsional displacement as differential value $(A-B)$ is equal to null, what complies with four-stroke engine's cycle of excitation.

Above-presented verification is evidence of correctness of implemented method of calculations, and proving that averaging of instantaneous angular speed based on $2^{\circ}$ sequence is sufficiently accurate. Moreover, the shape of the torsion wavelet (Fig. 2) can be compared with the model of excitation tangent forces function. The model wavelet of that force elaborated for three-cylinder laboratory engine is presented in Fig. 4. Very good coherence between angular position of the shaft engine the peak of model wavelet of excitation force and maximum peak of measured torsion must be noticed .

\section{Simplified analytical method of torsional vibration estimation}

All marine classification societies require calculation regarding the propulsion system operating parameters but they do not provide simplified formulas. There are several numerical algorithms [mostly based on the finite element method (FEM)] for propulsion system vibrations analyses [9]. But these numerical algorithms are not easy to use for ship crew as well as for autonomous SHM system. They are too complicated, time-consuming and expensive.

Table 1 Values of deviation index calculated for mean values of 1 revolution and 10 revolutions

\begin{tabular}{|c|c|c|c|c|c|c|}
\hline \multirow[t]{2}{*}{ Load } & \multicolumn{2}{|c|}{ Angular speed $A$} & \multicolumn{2}{|c|}{ Angular speed $B$} & \multicolumn{2}{|c|}{ Deviation index $\gamma$} \\
\hline & Mean of 1 rev. & Mean of 10 rev. & Mean of 1 rev. & Mean of 10 rev. & Mean of 1 rev. & Mean of $10 \mathrm{rev}$. \\
\hline $100 \mathrm{~kW}$ & 79.13621 & 79.10985 & 79.1456 & 79.10509 & $1.2 \mathrm{E}-4$ & $6.01 \mathrm{E}-5$ \\
\hline $140 \mathrm{~kW}$ & 79.06436 & 79.04746 & 79.05816 & 79.04055 & $7.8 \mathrm{E}-5$ & $8.7 \mathrm{E}-5$ \\
\hline $220 \mathrm{~kW}$ & 78.94818 & 79.00442 & 78.91894 & 79.00359 & $3.7 \mathrm{E}-4$ & $1.05 \mathrm{E}-5$ \\
\hline
\end{tabular}


Fig. 4 Model of tangential force wavelet of 3-cylinder 4-stroke engine

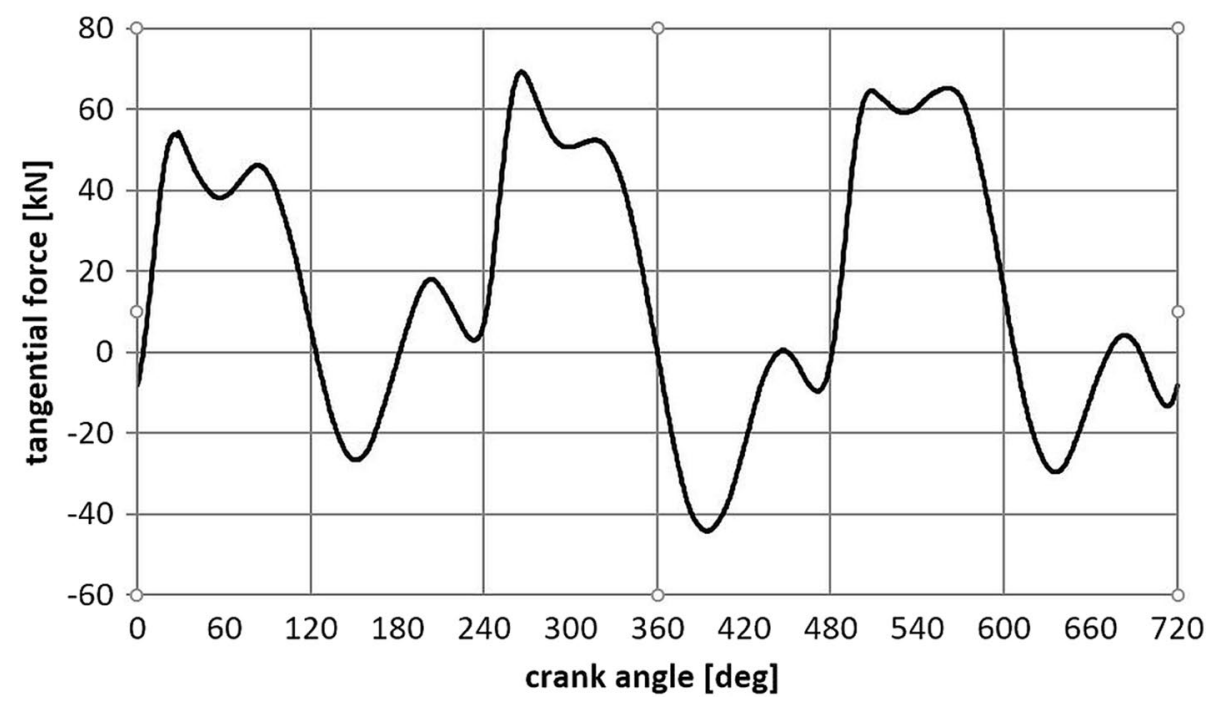

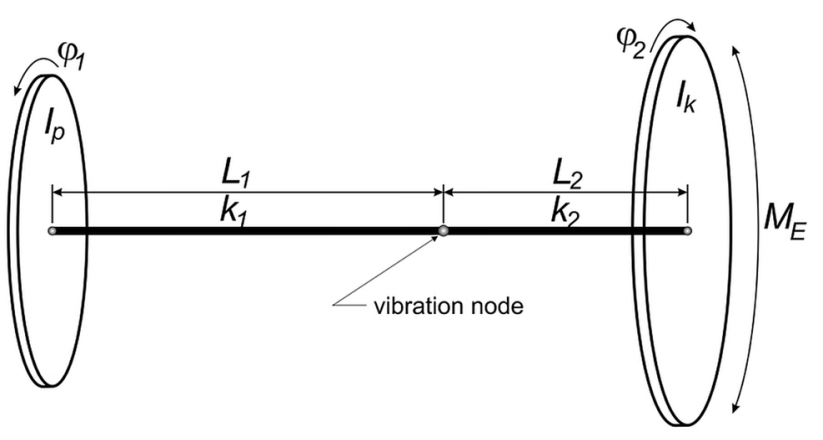

Fig. 5 Simplified model of the power transmission system for the torsional vibration calculation

According to the authors' knowledge, there is a lack of simplified calculation method of torsional vibration estimation. That method is crucial for SHM system which should have possibility to compare measured values (see Sect. 2) with prediction of future dynamic characteristics of the propulsion system and then lifetime estimation.

In the first analysis method, the authors assumed that two-node model is sufficient for the first estimation of the natural torsional vibration frequency and mode [10]. Propeller's polar moment of inertia is concentrated in one node and the crankshaft's polar moment of inertia is concentrated in second node. First mode of torsional vibrations is dominant for two-stroke, low-speed marine diesel engines. According to that assumption the stiffness of the crankshaft is infinite; only shaftline stiffness is taken into account. Simplified model of the power transmission system designed to estimate the torsional vibration is presented in Fig. 5. Polar moment of inertia of propeller with propeller shaft is marked as $I_{\mathrm{p}}$. Polar moment of crankshaft inertia (+ flywheels and reciprocating masses) with intermediate shaft is marked as $I_{k}$. Torsion stiffnesses of the shaft line are marked by $k_{1}$ and $k_{2}$. Vibration node location must be determined by the analysis method.

General description of torsional vibration can be described by the following formula (Eq. 5):

$I \ddot{\varphi}+C \dot{\varphi}+K \varphi=M_{\mathrm{E}}(t)$,

where $\varphi$ represents the rotational angle; $I$ represents the matrix of masses moments of inertia; $C$ represents the matrix of torsional dampings; $K$ represents the matrix of torsional stiffnesses and $M_{\mathrm{E}}$ represents the excitation moment.

Dampings have an insignificant influence on natural vibration frequency and mode. Natural vibrations are defined as motion without excitations. Therefore, Eq. 5 may be simplified and after several relatively simple transformations [10], equation for torsional natural frequency estimation can be presented in the following form:

$f_{n}=\frac{d_{\mathrm{e}}^{2}}{8} \sqrt{\frac{1}{2 \pi} \frac{G}{L_{\mathrm{s}}} \frac{I_{\mathrm{p}}+I_{\mathrm{c}}}{I_{\mathrm{p}} \cdot I_{\mathrm{c}}}}[\mathrm{Hz}]$,

where $I_{\mathrm{p}}$ represents the polar moment of inertia of propeller with propeller shaft; $I_{\mathrm{c}}$ represents polar moment of inertia of crankshaft with intermediate shaft; $G$ represents the shear modulus; $L_{\mathrm{s}}$ represents the shaftline length and $d_{\mathrm{e}}$ represents the external shaft diameter.

Estimation of polar moment of inertia of propeller must take into account added water mass [9]. Polar moment of inertia of added water should be summed up with propeller inertia (determined by designer) and propeller shaft. Typical shaftline has several sections with different diameters and lengths. Above-presented equations are derived for one uniform shaft. Therefore, substitute shaftline diameter should be determined. The substitute shaftline diameter can be solved from the following equation: 
$d_{\mathrm{e}}=\sqrt[4]{\frac{32 J_{m}}{\pi}} ; J_{m}=\frac{1}{L_{\mathrm{s}}} \sum_{i=1}^{n}\left(L_{i} \cdot J_{i}\right)$,

where $L_{i}$ represents the length of the shaft section; $J_{i}$ represents the polar moment of inertia of the shaft section and $J_{m}$ represents the medium value of the polar moment of inertia.

In the second step, the authors checked the influence of crankshaft stiffness on natural torsional vibration of the propulsion system. If we try to take into consideration the crankshaft stiffness, we have to calculate the equivalent polar moment of inertia of crankshaft $\left(I_{\mathrm{cs}}\right)$. We still assumed that only the first one node vibration mode is significant. The single straight line in the whole range of power transmission system is another authors' simplifying assumption. After several transformations, the equivalent polar moment of inertia of crankshaft can be determined as

$I_{\mathrm{cs}}=I_{\mathrm{c} 1}+I_{\mathrm{c} 2}\left(1+\frac{k_{2}}{k_{\mathrm{c} 1}}\right)+\cdots+I_{\mathrm{c} n}\left(1+\sum_{i=2}^{n} \frac{k_{2}}{k_{\mathrm{c}_{i}}-1}\right)$,

where $k_{2}$ represents the torsional stiffness between vibration node and crankshaft and $k_{\mathrm{c}_{i}}$ represents the torsional stiffness of $i$ th crank of crankshaft.

It should be stressed that the equivalent polar moment of inertia is much greater than the simple sum of cranks polar moments of inertia. Therefore, natural torsional frequency is smaller in the propulsion system model when taking crankshaft stiffness into consideration. An iterative process is needed for equivalent polar moment of inertia determination. But, just for the sake of estimation, we can assume that generally the location of torsional vibration node does not change.

Determination of the torsional resonance position is the most important problem-the SHM system must decide of the barred speed range values after emergency event. Natural frequency should be denoted as accurately as possible. The knowledge about torsional stress level in the shaftline and crankshaft might also be very important. The estimation of the stress level in the resonance and in the nominal main engine speed is significant. The stress amplitudes of torsional vibrations can be estimated on the basis of forced vibration equation (Eq. 5) and then the damping effect cannot be omitted. The best and simplest method for damping estimation is vibration magnifier determination [9]. But the confidence level of stress level determination is much lower in comparison with natural frequency determination even for detailed numerical method based on FEM, because of the difficulty of damping specification. There is no method for theoretical damping computing. Propeller damping is dominant in the marine propulsion system. Several quasi-empirical formulas describe propeller damping but the results may vary even for the order of magnitude. The authors assumed the simplest way of damping estimation. On the basis of our own experience, the torsional vibration magnifier in the resonance is approximately equal to $15 \pm 3$ [9]. Our knowledge is similar to that of other researchers; for instance is similar to value recommended by MAN B\&W. Vibration magnifier for any excitation frequency can be defined as a quotient of torsional vibration amplitude to static torsion under the same torque value. Static torsional stress value is easy to calculate on the basis of well-known strength of materials' formula. Dependence between vibration magnifier $\left(Q_{\omega}\right)$ for any rotational speed size $\left(\omega_{\mathrm{E}}\right)$ and vibration magnifier $\left(Q_{\mathrm{R}}\right)$ in the resonance $\left(\omega_{\mathrm{N}}\right)$ has been derived by authors and has the following form:

$Q_{\omega}=\frac{1}{\sqrt{\left[1-\left(\frac{\omega_{\mathrm{E}}}{\omega_{\mathrm{N}}}\right)^{2}\right]^{2}+\frac{1}{Q_{\mathrm{R}}^{2}}\left(\frac{\omega_{\mathrm{E}}}{\omega_{\mathrm{N}}}\right)^{2}}}$.

Real torsional stress level for given revolutions is equal to vibration magnifier $\left(Q_{\omega}\right)$ multiplication by static torsional stress. The torsion moment (torque) for given revolutions has to be known for quasi-static stresses calculation. The moment can be easily estimated by measurements described in Sect. 2 and based on Instantaneous Angular Speed methodology. The torsional loads can be also observed on the base of mean indicated pressure (mip) measured in each cylinder. All those procedures can be implemented in the SHM system. But for starting estimations of the torque (and mip) the data of the main engine producer's can be used. An example calculation of mean indication pressure, vibration magnifier and quasistatic torsional stress level is presented in Fig. 6. It has been performed for slow-speed, two-stroke, seven-cylinder main engine: MAN B\&W 7 S70 MC-C type.

Maximal torsional stress level of the power transmission system is estimated by multiplication the vibration magnifier and static torsional stress level for given engine revolutions. The authors' estimation was compared with the detailed FEM calculation (performed by independent design office) and measurements (measured by the other specialized team). The comparison is presented in Fig. 7. Damping magnifier in the resonance $\left(Q_{\mathrm{R}}\right)$ can be corrected in relation to measurements and was modified in the authors' simplified method. This is the reason for the high consistency of the simplified method with the measurements in vibration resonance. The verification shows that error level between the proposed methodology and "reality" is acceptable. The highest differences are around resonance revolutions and were caused by damping coefficients assumptions. 


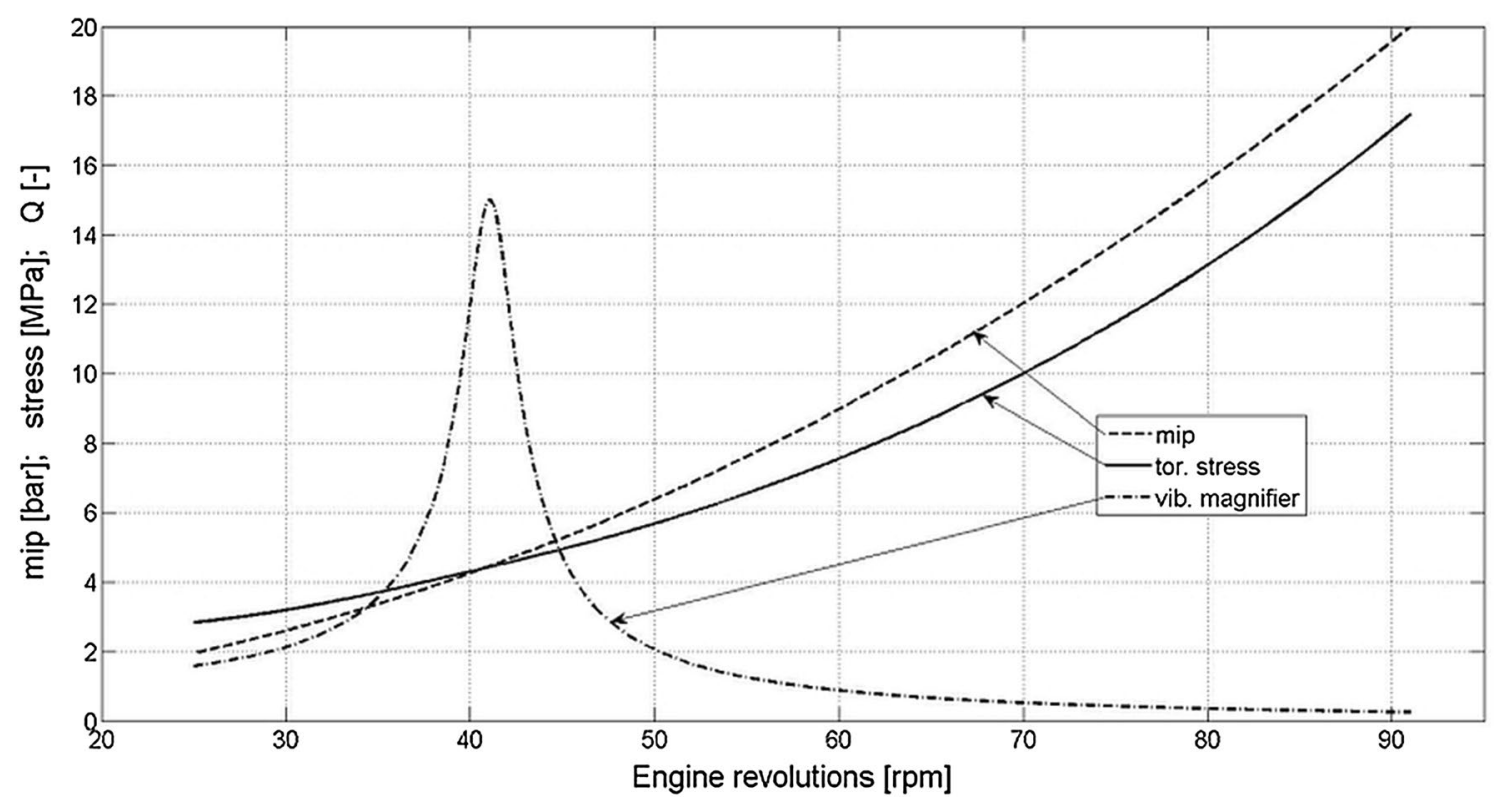

Fig. 6 Data useful for dynamic torsional stress level estimation

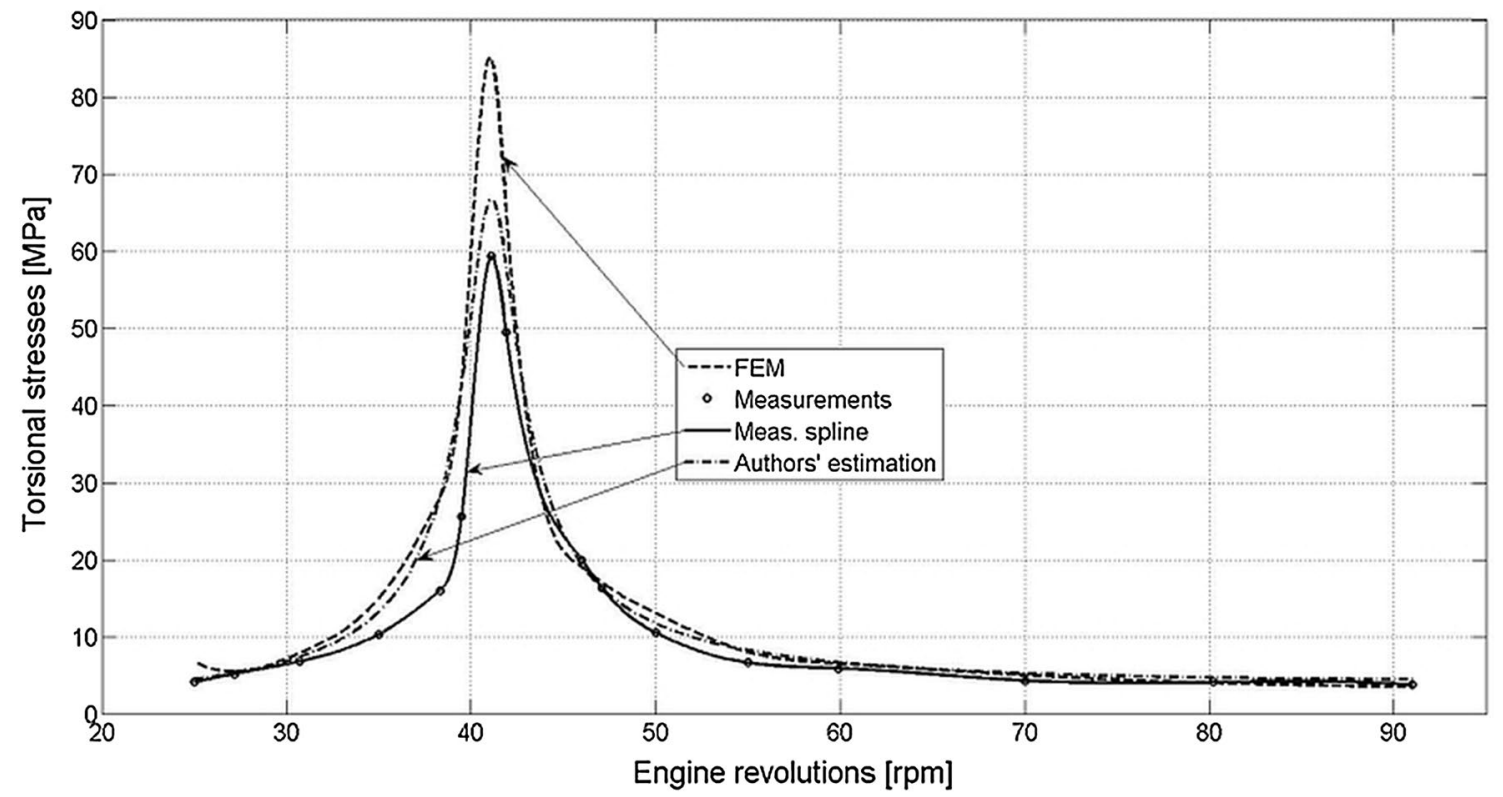

Fig. 7 Torsional stress level of the container ship propulsion system

\section{Preliminary application of measurement system}

A number of experiments were carried out to verify the presented methodology. First part of experiment was focused on detection of fuel delivery malfunction. Typical problems in exploitation are leakage of high pressure piping or wear of high pressure pump pistons. As result of above problems, not sufficient dose of fuel is delivered to a fuel valve. To detect potential changes, series of measurements under normal conditions and with simulated failure of fuel pump were conducted. It was assumed that different parameters of fuel delivery must affect parameters of combustion and to cause different runs of force value during working stroke. If would be possible to detect and evaluate deviation caused by such changes, is obviously possible to detect malfunction of injection valves related to clogging 
of nozzle's holes or improper fuel injection pressure. All experiments and their analyses proved that the presented methodology might be useful in the planed SHM system.

As was said previously, first the detection of fuel delivery malfunction was performed. Not sufficient dose of fuel causes deterioration of combustion process, changes of gas force maximum value and mean effective pressure. Deviations of gas force run must affect instantaneous value of torque and obviously must have impact at torsional vibrations of a shafting. Malfunction of fuel system was simulated in way of creating controlled leakage from fuel pump responsible for delivery to cylinder number two. Second approach to examination of detection possibility was based on application of two different fuel valves, with different construction of nozzles. One set of valves with 9 holes in nozzle and $150^{\circ}$ angle of spraying holes, the second one had 8 holes in nozzle and $158^{\circ}$ angle of spraying hole spraying. Example of different run of in-cylinder pressure and injection pressure because of different nozzles of fuel valve (10 holes versus 9 holes) is presented in Fig. 8.

Records of torsional vibrations are presented as function of instantaneous value of torsion angle $\varphi$ in domain of a crank position. Figure 9 presents example of torsion record encompassing four subsequent revolutions what is two working cycles of four-stroke engine. Raw signal is quite sharp, but even before smoothing, three peaks of torsion reflecting contribution of everyone from three cylinders can be spotted. Raw signal after smoothing by Savitzky-Golay filter gives much clearer picture. Torsional vibration after filtration is presented in Fig. 9 by a continuous line. Angular position of

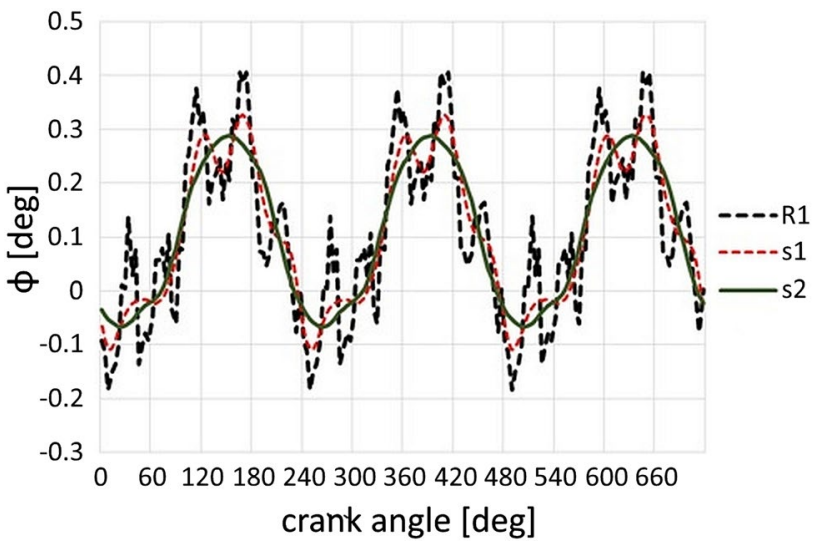

Fig. 9 Raw signal waveform of torsional deflection encompassing two cycles (dashed lines) and waveform of torsional deflection after smoothing by Savitzky-Golay filter (continuous line)

each peak and value of the magnitude can be easy observed. Such picture lets make preliminary evaluation of gas force quality in every cylinder.

Much more information is included in FFT spectrum of torsional deflection's run. The engine used for experiments is generator's mover, thus its basic rotational speed is $750 \mathrm{rev} / \mathrm{min}$ for $50 \mathrm{~Hz}$ current frequency. In test bed, it is possible to set up different revolutionary speed from range of $650-750 \mathrm{rev} / \mathrm{min}$. and rotational frequency from $10.82 \mathrm{~Hz}$ to $650 \mathrm{rev} / \mathrm{m}$ to $12.5-750 \mathrm{~Hz}$. Assuming different torsional behaviour at different revolutionary speed, subsequent experiment was carried out. Keeping constant load

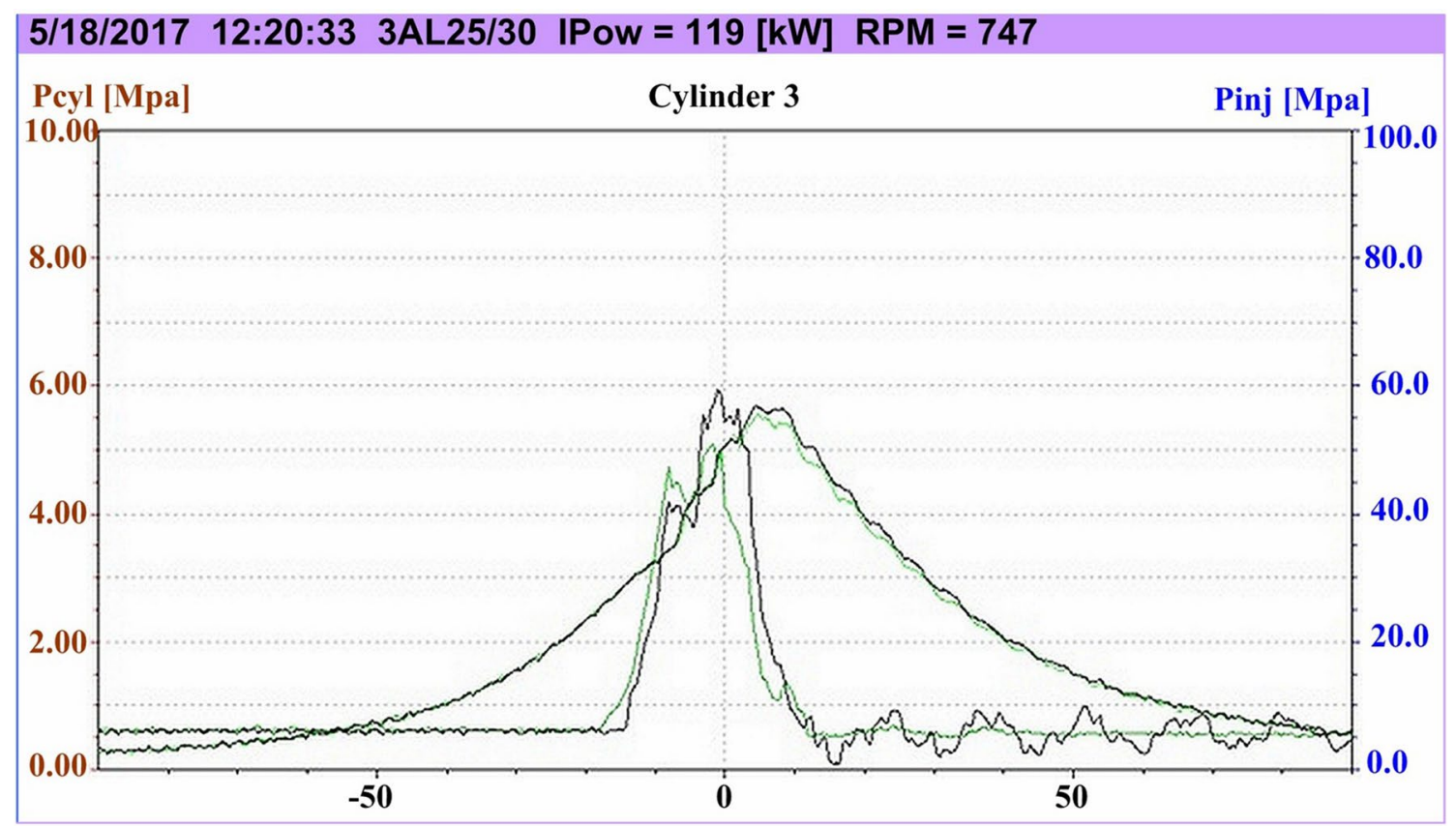

Fig. 8 Indicated pressures for fuel injectors with different number of nozzles 
Fig. 10 Harmonic spectrum of torsional deflection's raw signal, a $650 \mathrm{rev} / \mathrm{min}$; b $700 \mathrm{rev} / \mathrm{min}$ a

0.003

0.0025

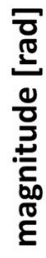

0.002

0.0015

0.001

0.0005

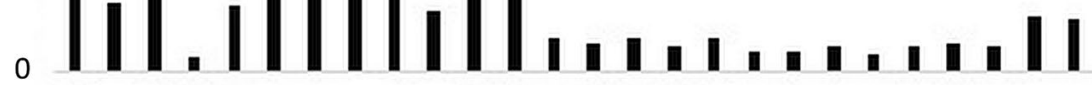

乌ి

frequency $[\mathrm{Hz}]$

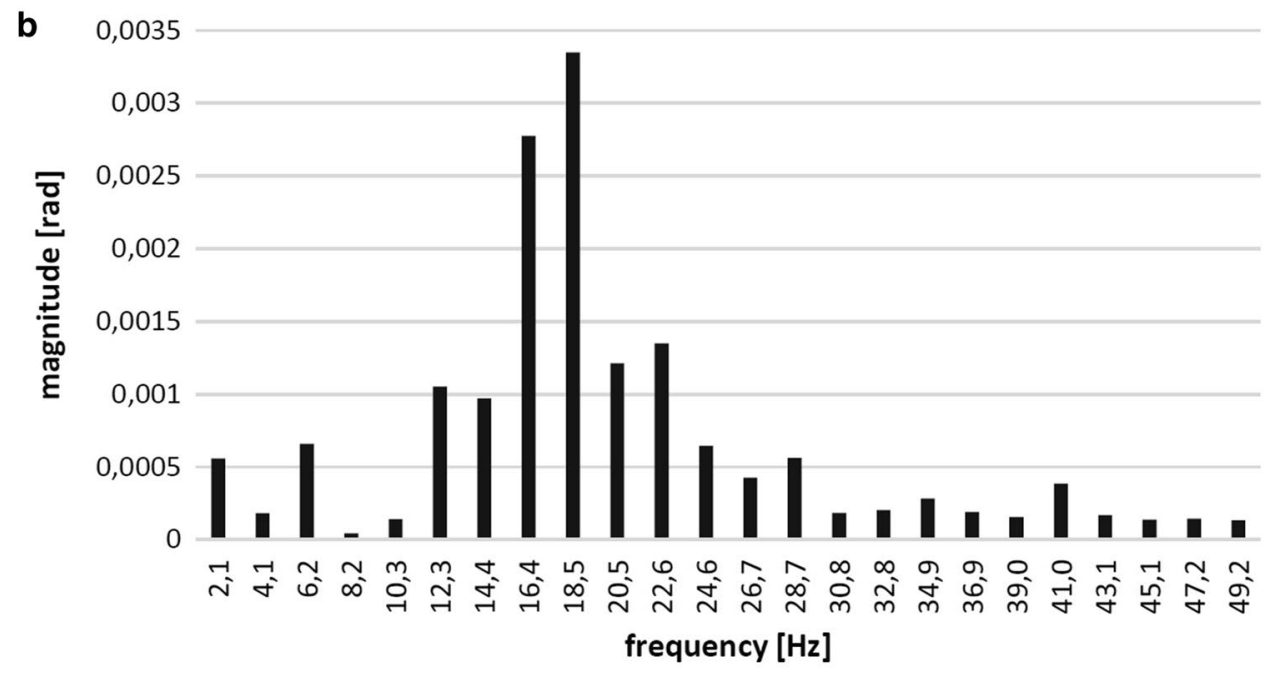

of generator, rotation of the engine was set up at three different levels, 650, 700 and $750 \mathrm{rev} / \mathrm{min}$. In all cases, run of torsional deflection was different, what was detected after spectral analysis of basic orders. Spectra of magnitude of harmonics in range of $50 \mathrm{~Hz}$ of raw signal for $650 \mathrm{rev} / \mathrm{min}$ and $700 \mathrm{rev} / \mathrm{min}$ are presented in Fig. 10. Different values of magnitude can be observed, especially in frequency brackets up to $25 \mathrm{~Hz}$. The observation is in accordance with diesel generator's technical documentation, where it is stated that higher magnitude of harmonics occurs when engine is running $700 \mathrm{rev} / \mathrm{min}$ due to approach to resonance frequency.

To get clearer picture of harmonics, values of magnitude of orders number $0.5,1,1.5,2,2.5,3,3.5$, 4 were separated. Torsional magnitudes of harmonic orders recorded during engine run with revolutionary speed of 650, 700 and 750 rev/min are presented in Fig. 11. Picture shows, that order number 1.5 , related to contribution of three cylinders during

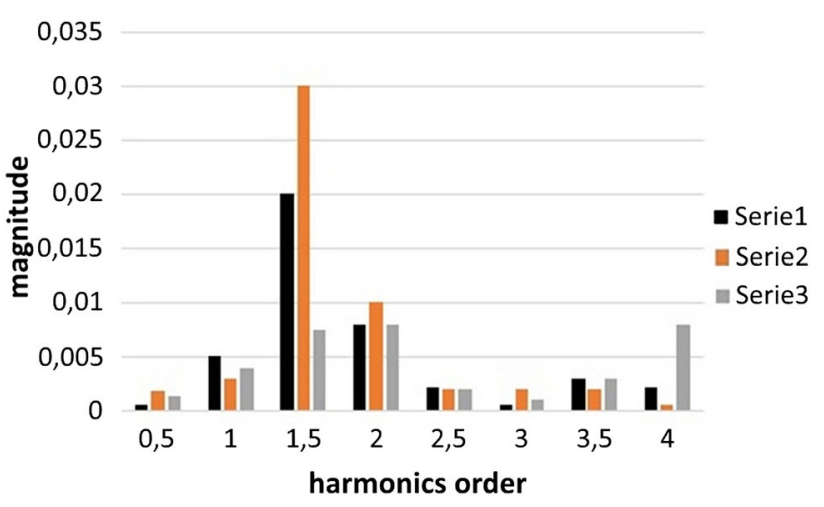

Fig. 11 Harmonic spectrum of torsion of $650 \mathrm{rev} / \mathrm{min}$ (serie1), 700 $\mathrm{rev} / \mathrm{min}$ (serie2) and $750 \mathrm{rev} / \mathrm{min}$ (serie3) 


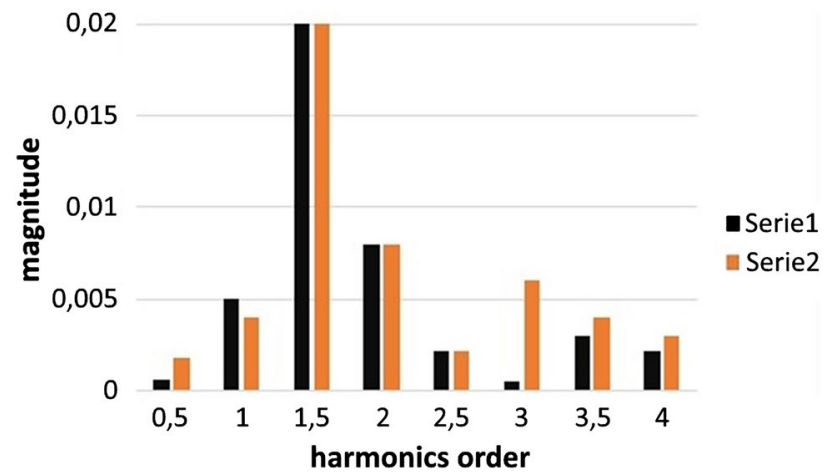

Fig. 12 Harmonic spectrum of torsion; healthy engine (serie1) and malfunction of injection (serie2)

the cycle has highest magnitude for $700 \mathrm{rev} / \mathrm{min}$ and lowest for $750 \mathrm{rev} / \mathrm{min}$ (dedicated for normal exploitation). Those results are according to expectation, and confirm reliability of the measurement method.

Very interesting results coming out from comparison of harmonics spectra obtained after FFT of torsional vibrations registered with simulation of fuel leak from injection system and run of engine in proper condition. In that case, magnitudes of order number 1.5 are equal, but magnitudes of order number 0.5 were different. Magnitude of run with malfunction has much higher value in comparison with healthy engine run; that effect can come out from typical reaction of speed regulator whose role is to keep constant speed. When one cylinder contribution drops, system provides higher fuel dose for other cylinders, what results with higher gas force and increase of torque. FFT spectrum does not give answer what is number of affected cylinder, but detection is possible after analysis of IAS waveform. It means that malfunction of one cylinder was detected (Fig. 12).

Impact of injector nozzle construction at torsional vibration is analysed as the next step of system application. The experiment relayed at confrontation of torsional vibrations being measured at different load levels repeated for two types of injectors. Measurement started from level of $65 \%$ of nominal load, and subsequently $70 \%$ and $75 \%$ was set up. First part of experiment was carried out after installation of injectors with 9 spraying holes and holes angle $150^{\circ}$. After warming up, engine was set up at planned load levels and 5 subsequent records were done for each load. The procedure was repeated after installation of second type of injectors, with 8 spraying holes and angle of $158^{\circ}$. Obtained results were interesting and quite promising as subject for further investigation. At low level of load, different runs of torsion waveforms in domain of crank angle were observed. For better comparison, results of measurements, after filtration, were presented as function of deviations from mean value of cycle. It enabled avoiding errors due to phenomenon of waving of torsion waveform with low frequency due to speed governor action. Different maximum value and slight shift between peaks positions occurred for all three cylinders (see Fig. 13). Comparison of waveforms in way of differential value in crank angle domain shows differences at level close to maximum torsion; that behaviour of function is observed always when shift of peaks phase occurs. Above observations let assume, that different angle of spray holes and its number changes condition of combustion strong enough to be transferred to the shaft.

Increase of load up to $75 \%$, resulted with significant transformation of waveform relations. Level of correlation is very high, phase shift between peaks disappeared, only differences between maximum values can be spotted. It means that at higher load impact of nozzle construction descends. Subsequent rise of load up to $75 \%$ of nominal almost eliminated differences between waveforms. Increase of fuel dose injected in cycle and dynamics of combustion caused elimination of differences between gas force creation processes, so eventually differences are too weak to be reflected by crankshaft torsion. Waveforms of differential value of torsion recorded with two types of injectors at loads implemented for experiment are presented in Fig. 14. It is obvious that rise of load is eliminating differences between
Fig. 13 Comparison of oscillation, load 65\%, injector with 9 holes (serie1), injector with 8 holes (serie2)

\section{Load 65\% MCR}

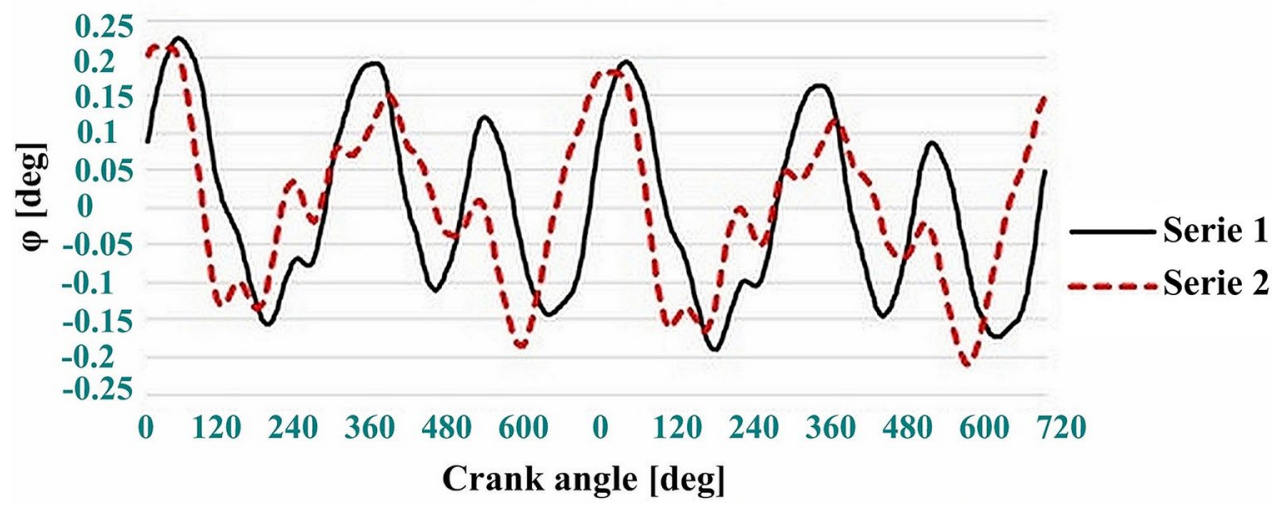


Fig. 14 Waveform of differential comparison of torsional magnitudes caused by number of injector holes; load 75\%serie $1,70 \%$-serie $2,65 \%$ serie3

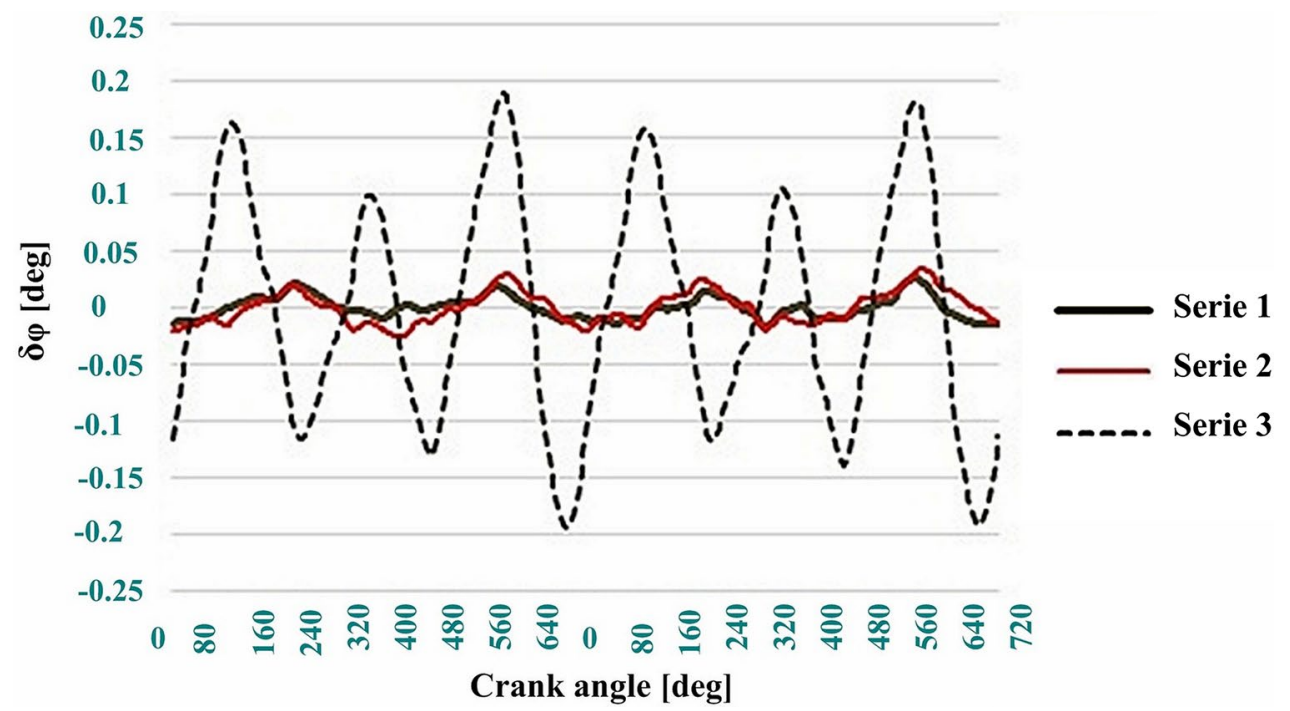

dynamics of torsional reaction of the shaft, due to combustion parameters.

Results obtained during experiment with different injectors nozzles, give interesting information about accuracy of the method. Possibility to detect the difference between torsional vibration caused by installation of two types of nozzles, let assume that other deviations or disturbances related to combustion process can be detected. Further steps of method's development shall be directed to proof obtained results by repetition of experiment under various outer condition. It is absolutely necessary to define impact of atmospheric pressure, humidity and temperature at torsional deflection waveforms.

\section{Conclusions}

Proposed method of torsional deviation measurement is very convenient due to easy way of mounting of measurement system elements, simple and not expensive construction, high durability and reliability. Data processing is not complicated and can be proceed in autonomous monitoring system. High frequency of laser emitter gives high level of accuracy and ensures broad range of implementation, according to evaluation calculations; system is effective up to 4000 $\mathrm{rev} / \mathrm{min}$ what covers all ranges of diesel engines. Proposed method seems to be good tool for verification of various kinds of theoretical models simulating dynamic of diesel engines (Sect. 4). Discovering straight relations between registered torsion variations and engine malfunctions, one is creating reliable basis for formulation of diagnostics conclusions. Possibility of detection of fuel system malfunction will be very important tool for SHM system.

The presented calculation methodology of torsional vibration estimation can be an important part of SHM system.
The results based on authors' methodology have been compared with the analogical calculation made by independent numerical programs in an independent design office as well as compared with the measuring data obtained by other independent specialized team. The results conformity is good. The results obtained from authors' methodology are usually overestimated in comparison with the detailed calculation, if the crankshaft elasticity is not taken into account. The method based on Eq. 8 is more precise but also a little bit more laborious. In the authors' opinion presented methodology might prove useful for marine SHM systems. In authors opinion, both methods in cooperation, might be a base of monitoring system of marine propulsion system.

Open Access This article is distributed under the terms of the Creative Commons Attribution 4.0 International License (http://creativeco mmons.org/licenses/by/4.0/), which permits unrestricted use, distribution, and reproduction in any medium, provided you give appropriate credit to the original author(s) and the source, provide a link to the Creative Commons license, and indicate if changes were made.

\section{References}

1. Andersen IMV, Jensen JJ (2014) Measurements in a container ship of wave-induced hull girder stresses in excess of design values. Mar Struct 37:54-85

2. Senjanović I, Vladimir N, Tomić M, Hadžić N, Malenica Š (2014) Some aspects of structural modelling and restoring stiffness in hydroelastic analysis of large container ships. Ships Offshore Struct 9(2):199-217

3. Lin TR, Pan J, O'Shea PJ, Mechefske CK (2009) A study of vibration and vibration control of ship structures. Mar Struct 22:730-743

4. Geveci M, Osburn AW, Franchek MA (2005) An investigation of crankshaft oscillations for cylinder health diagnostics. Mech Syst Signal Process 19:1107-1134

5. Nestorides EJ (1958) A handbook on torsional vibration. Cambridge University Press, Cambridge 
6. Wilson WK (1963) Practical solution of torsional vibration problems. Chapman \& Hall LTD, London

7. Lin TR, Tan ACC, Ma L, Mathew J (2011) Estimating the loading condition of a diesel engine using instantaneous angular speed analysis. In: Proceedings of the 6th world congress on engineering asset management, Cincinatti, Ohio, USA, 3-5 October 2011. https://eprints.qut.edu.au/46609/1/46609A.pdf

8. Dereszewski M, Charchalis A, Polanowski S (2011) Analysis of diagnostic utility of instantaneous angular speed of a sea going vessel propulsion shaft. J KONES 18(1):77-83
9. Murawski L (2003) Static and dynamic analyses of marine propulsion systems. Oficyna Wydawnicza Politechniki Warszawskiej, Warsaw

10. Murawski L, Charchalis A (2014) Simplified method of torsional vibration calculation of marine power transmission system. Mar Struct 39:335-349

Publisher's Note Springer Nature remains neutral with regard to jurisdictional claims in published maps and institutional affiliations. 